\title{
The effect of indomethacin on uterine contractility and luteal regression in pregnant rats at term
}

\author{
Anna-Riitta Fuchs*, Y. Smitasiri and U. Chantharaksri \\ Laboratory for Reproductive Physiology, Department of Obstetrics \& Gynecology, \\ Chulalongkorn University Medical School, Bangkok, Thailand
}

\begin{abstract}
Summary. Treatment of pregnant rats with $1 \mathrm{mg}$ indomethacin $/ \mathrm{kg}$ twice daily i.m. beginning on Day 20 delayed the onset of parturition by about $21 \mathrm{hr}$ and prolonged the duration of spontaneous parturition by $4 \mathrm{hr}$. Plasma progesterone and oestradiol levels were determined in daily samples of peripheral blood, and uterine contractions were recorded before and during parturition by means of small, chronically implanted intrauterine balloons which were connected to pressure transducers via fluid-filled catheters. Indomethacin treatment did not inhibit or suppress spontaneous or oxytocin-induced contractions, which were of the same intensity in indomethacin-treated as in control rats. Parturition was induced with oxytocin in the same proportion of treated and control rats, but its induction was not successful in treated rats until 1 day later than in controls. The onset of parturition was always related to the plasma progesterone level, which declined at a slower rate in indomethacin-treated than in control rats, reaching baseline values approximately 1 day later in the treated animals. The appearance of $20 \alpha$-hydroxysteroid dehydrogenase in the CL of pregnant rats normally occurs on Day 21 of gestation, but activity was not observed until about $1(0-3)$ day later in the indomethacin-treated rats, indicating that luteolysis was retarded. Prostaglandin F-2 $\alpha$ infusions given on Day 21 reversed the effects of indomethacin treatment on plasma progesterone, luteal $20 \alpha-$ hydroxysteroid dehydrogenase activity and the timing and duration of parturition, and reduced the high perinatal mortality associated with indomethacin treatment, suggesting that the effects of indomethacin were related to its inhibitory action on prostaglandin synthetase activity. It is concluded that, in rats, indomethacin exerts its effects on parturition through inhibition of luteal regression which was significantly retarded but not prevented, and that indomethacin does not have a direct effect on myometrial contractility.
\end{abstract}

\section{Introduction}

Aspirin, indomethacin and other drugs that inhibit prostaglandin (PG) biosynthesis are known to delay the onset of parturition and prolong its duration in rats (Aiken, 1972; Chester, Dukes, Slater \& Walpole, 1972), rhesus monkeys (Novy, Cook \& Manaugh, 1974) and women (Lewis \& Schulman, 1973; Collins \& Turner, 1975a), supporting the widely held view (see Karim, 1975) that endogenous PGs are of importance for the normal course of parturition in several species, although their exact role is still obscure.

Parturition is the culmination of a series of events taking place at term, and tissue PGs of placental, uterine or ovarian origin could be involved in several of these events. It has been postulated that uterine PGs contribute significantly to myometrial contractions since aspirin and indomethacin suppress both the synthesis of PGs by and the contractions of the isolated rat uterus in vitro (Aiken, 1972; Vane \& Williams, 1973; Williams, Sneddon \& Harney, 1974; Bauduoin-Legros, Myer \&

* Present address: Biomedical Division, The Population Council, The Rockefeller University, New York, New York 10021, U.S.A. 
Worcel, 1974). On the other hand, studies on the effect of PGs on the contractility of the pregnant rat uterus in vivo did not support the hypothesis (Fuchs, 1972): the sensitivity of the uterus to stimulation by PGE-1, PGE-2 or PGF-2 $\alpha$ diminished markedly at term, and all three compounds failed to induce parturition while oxytocin was highly effective. Uterine contractility in vitro is often different from that observed in the intact organ in vivo (Fuchs \& Fuchs, 1963). The aim of the present investigation was therefore to study the effect of a known PG synthetase inhibitor, indomethacin, on uterine contractility and the response to oxytocin of pregnant rats before and during parturition, as well as to examine its effect on other factors that are of importance for the onset of parturition in this species, such as luteal regression. Plasma progesterone and oestradiol levels were therefore determined, and luteal $20 \alpha$-hydroxysteroid dehydrogenase (20 $\alpha$-HSD) activity was monitored, since in rats this enzyme is a sensitive indicator of luteolysis (Wiest \& Kidwell, 1969). Preliminary results have already been reported (Fuchs, Smitasiri \& Chantaraksri, 1974).

Indomethacin was chosen as the PG synthetase inhibitor because it is the most potent of the available inhibitors (Flower, 1974) and has been widely used for in vitro and in vivo studies. Although it also inhibits certain other enzymes, notably phosphodiesterase and PG 15-dehydrogenase, the concentrations required are much higher than those inhibiting PG synthetase (Flower, 1974), which are in the range achieved by therapeutic doses of the drug.

\section{Materials and Methods}

The experiments were carried out with Sprague-Dawley-derived rats from various breeders, because no single source was available in Bangkok. The animals were housed in air-conditioned rooms, under natural lighting conditions ( $12 \mathrm{hr}$ light $/ 24 \mathrm{hr})$ and were fed commercial rat pellets imported from Singapore.

On Day 19 of gestation (Day 1 = day of finding spermatozoa in the vaginal lavage), the rats were fitted with an indwelling catheter inserted via the right jugular vein into the right ventricle (PE 50, i.d. $0.58 \mathrm{~mm}$; o.d. $0.96 \mathrm{~mm}$ ) under sodium pentobarbital anaesthesia (30 mg Nembutal $/ \mathrm{kg}$ i.p.). This catheter was used for administration of drugs and for collection of blood samples $(0.5 \mathrm{ml}$ each time). For recording of intrauterine pressure from conscious animals, a balloon-tipped catheter was inserted into the apex of the right uterine horn through a small transverse incision which was closed by a purse-string suture (5-0 silk) around the connecting catheter (PE 20, i.d. $0.38 \mathrm{~mm}$; o.d. $1 \cdot 1 \mathrm{~mm}$ ). Both catheters were passed subcutaneously to the neck of the animals and exteriorized there through a puncture of the skin, as previously described (Fuchs, 1969).

Oxytocin (Syntocinon:Sandoz) was infused intravenously at the rate of $1 \mathrm{mU} / \mathrm{min}$ for $2 \mathrm{hr}$ beginning at 12.00 hours, followed by $2 \mathrm{mU} / \mathrm{min}$ for $2 \mathrm{hr}$ on Days 21,22 and 23. This dosage mimics normal uterine contractions and induces parturition in $80 \%$ of rats on Day 22 (Fuchs \& Poblete, 1970). Parturition was considered to have been induced if the expulsion of the litter started during the infusion. PGF-2 $\alpha(125 \mu \mathrm{g})$ was infused i.v. at the rate of $0.5 \mu \mathrm{g} / \mathrm{min}$ for $4 \mathrm{hr}$, on Day 21 only or on Days 22 and 23. This dose causes luteolysis and induces premature parturition in all rats infused on Days 18 or 20 of gestation (Fuchs, Mok \& Sundaram, 1974). Control rats received an equal volume $(4 \mathrm{ml})$ of $0.9 \%(\mathrm{w} / \mathrm{v}) \mathrm{NaCl}$. Indomethacin was dissolved in sesame oil and given i.m. twice daily (at $07.30-08.30$ and $17.30-18.30$ hours) from Day 20.

Blood was collected in ice-cooled, heparinized tubes. Plasma was separated, frozen and kept at $-20^{\circ} \mathrm{C}$ and sent abroad frozen for measurement of progesterone by the radioimmunoassay method of Thorneycroft \& Stone (1972), and of oestradiol by the method of Edqvist \& Johansson (1972). Progesterone was assayed in duplicate samples of 25-50 $\mu \mathrm{l}$ plasma, extracted with $1 \mathrm{ml}$ petroleum ether, using an antiserum raised in rabbits against progesterone-11-succinyl-bovine serum albumin. Plasma from ovariectomized adrenalectomized rats gave a blank value of $<25 \mathrm{pg}$. Recovery of added progesterone (250-5000 pg) gave a curve which was superimposable with the standard curve. Oestradiol was measured in duplicate samples of $100 \mu \mathrm{l}$ plasma, extracted with $1 \mathrm{ml}$ diethyl ether, using an antiserum raised in sheep against oestradiol-17 $\beta-6(\mathrm{O}$-methyloxime)-bovine serum albumin, which is highly specific and shows $<11 \%$ cross-reaction with oestrone. The plasma blank had a value 
of $45 \mathrm{pg}$. The interassay coefficient of variation was $8 \%$ in both assays, and all values reported are uncorrected for recovery which was over $90 \%$ in both assays.

Histochemical techniques described by Balogh (1964) were used to demonstrate the presence of 20a-HSD activity in ovaries removed at 11.00 hours on Days 20, 22 and 23. Estimation of the contractile response to oxytocin or PG injections or infusions was made by visual inspection of the records with respect to amplitude and frequency of the intrauterine pressure changes as well as the duration of such increased activity. The effect of indomethacin treatment on these responses was assessed by comparison with the reactions of control rats given the same oxytocin or PG injections and recorded simultaneously. A dose of $1 \mathrm{mg}$ indomethacin $/ \mathrm{kg}$ twice daily was used for all experiments because preliminary studies had shown that doses of 2 and $5 \mathrm{mg} / \mathrm{kg}$ twice a day were highly toxic.

\section{Results}

\section{Parturition}

The occurrence of parturition in the various groups and the data on the length of gestation, the duration of parturition, and maternal and perinatal mortality are summarized in Table 1.

The oil-injected control rats received physiological saline or oxytocin infusions on Days 21,22 and 23. In the saline-infused controls, parturition occurred at the same time as in intact normal rats between late afternoon of Day 22 and afternoon of Day 23 . Oxytocin induced parturition in $80 \%$ of the rats, advancing it by about $14 \mathrm{hr}$. PGF- $2 \alpha$ had no effect on the length of gestation and duration of parturition in control rats.

There were 6 groups of animals treated with indomethacin: Groups 4 and 5 were infused daily with saline or oxytocin respectively, beginning on Day 21 ; PGF-2 $\alpha$ was infused to Group 6 and 8 animals on Day 21, and to animals in Groups 7 and 9 on Days 22 and 23. Rats in Groups 8 and 9 were also given oxytocin infusions on Days 22 and 23.

Indomethacin treatment prolonged the length of gestation by approximately 1 day (Group 4); mean gestation length was $21 \mathrm{hr}$ longer than in control rats (Group 1). The onset of parturition was more variable than in the control rats, at the normal time in some and prolonged in others. In two animals parturition was completely prevented and the rats died on Day 25 . In comparison to the oxytocin-treated control rats (Group 2), oxytocin induction of parturition in indomethacin-treated rats (Group 5) was delayed by an average of $20 \mathrm{hr}$. The duration of spontaneous parturition was considerably prolonged in indomethacin-treated rats, but was normal when oxytocin was also administered. Maternal and perinatal mortality were greater in indomethacin-treated rats. Most perinatal deaths occurred shortly after parturition, a few shortly before. Although maternal and perinatal mortality was often associated with difficult births, many perinatal deaths occurred when parturition was apparently normal.

PGF-2 $\alpha$ given on Day 21 reversed the effects of indomethacin on gestation length and duration of parturition, and perinatal mortality was also significantly reduced (Group 6). Oxytocin infusions induced parturition in all of these rats on Day 22 (Group 8).

When PGF-2 $\alpha$ was administered on Day 22 instead of Day 21, the onset of parturition was correspondingly delayed by about $16 \mathrm{hr}$ (Group 7). No pregnancies were abnormally prolonged in any of the PGF-2 $\alpha$-treated animals. Induction of parturition with oxytocin was not successful on Day 22 when PGF-2 $\alpha$ was given at the same time, but was successful on Day 23 in the rats that had received PGF-2 $\alpha$ on Day 22 (Group 9). There appeared to be no potentiation of the oxytocin effect by the simultaneous administration of PGF-2 $\alpha$.

\section{Influence on uterine contractions}

No suppression of uterine contractile activity was observed in 10 rats for which records were taken continuously from Day 20 when the indomethacin treatment was started and until parturition (Text-figs $1 \mathrm{a}$ and $1 \mathrm{~b}$ ). Increasing the dose to $5 \mathrm{mg} / \mathrm{kg}$ did not result in inhibition of uterine contrac- 
Anna-Riitta Fuchs et al.

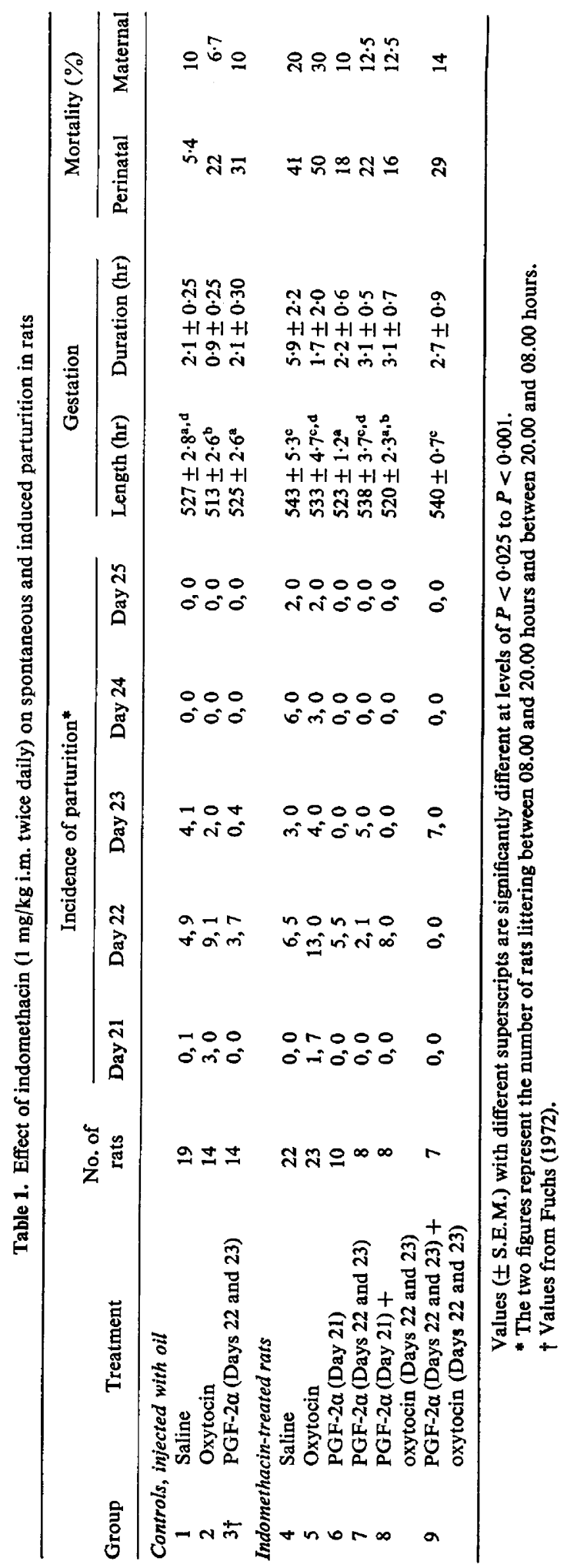


tions or the response to oxytocin infusions as seen in Text-fig. 1 (c), provided that the rats remained in reasonably good physical condition. The responses to frequent i.v. injections of various doses of oxytocin were also quite similar to those in control rats (Text-fig. 1d). Spontaneous activity was not suppressed, in fact there was more spontaneous activity in many of the indomethacin-treated rats than in control rats (Text-fig. 1a). The pattern of uterine response to oxytocin was altered in some instances, but its magnitude was not significantly affected.

\section{Infiuence on plasma progesterone}

Under normal conditions the plasma progesterone levels of pregnant rats remain high until Day 20 of gestation, fall rapidly on Day 21 and reach nonpregnant levels by the morning or afternoon of Day 22 (Wiest \& Kidwell, 1969).

The plasma progesterone concentrations obtained in the present study are shown in Table 2 . The values in the morning of Day 20 were more variable than in our previous studies, perhaps reflecting the somewhat heterogeneous rat population used in Bangkok. In the control groups, plasma progesterone fell below $10 \mathrm{ng} / \mathrm{ml}$ on the afternoon of Day 22. In oxytocin-infused rats, plasma progesterone decreased more rapidly on Day 21 and had reached lower levels by the morning of Day 22 than in the saline-infused control group, suggesting that oxytocin may have some luteolytic effect, but the differences were not statistically significant.

Table 2. Mean \pm S.E.M. plasma progesterone levels (ng/ml) in pregnant rats (no. in parenthesis) given indomethacin in oil (i.m.) from Day 20

\begin{tabular}{|c|c|c|c|c|c|}
\hline $\begin{array}{c}\text { Day of } \\
\text { gestation } \\
(08.00-09.00 \text { hours })\end{array}$ & $\begin{array}{c}\text { Group } 1 \\
\text { (saline-treated } \\
\text { controls) }\end{array}$ & $\begin{array}{l}\text { Group } 2 \\
\text { (oxytocin-treated } \\
\text { controls) }\end{array}$ & $\begin{array}{c}\text { Group } 4 \\
\text { (indomethacin } \\
+ \text { saline) }\end{array}$ & $\begin{array}{l}\text { Group } 5 \\
\text { (indomethacin } \\
\text { + oxytocin) }\end{array}$ & $\begin{array}{c}\text { Group } 6 \\
\text { (indomethacin } \\
+ \text { PGF-2 } \alpha \text { ) }\end{array}$ \\
\hline & (6) & (8) & (10) & (12) & (8) \\
\hline 20 & $41 \cdot 3 \pm 5 \cdot 0$ & $107 \cdot 3 \pm 13$ & $75 \cdot 6 \pm 13$ & $73 \cdot 7 \pm 8.9$ & $56.7 \pm 8.5$ \\
\hline 21 & $50 \cdot 2 \pm 7.4$ & $58.6 \pm 7.2$ & $67 \cdot 3 \pm 8.8$ & $76.7 \pm 7 \cdot 3$ & $52 \cdot 2 \pm 7 \cdot 5$ \\
\hline 22 & $17 \cdot 0 \pm 2 \cdot 6$ & $10.3 \pm 1.8$ & $32 \cdot 0 \pm 13$ & $26 \cdot 3 \pm 8 \cdot 3$ & $16 \cdot 8 \pm 4 \cdot 2$ \\
\hline 23 & $\begin{array}{c}8 \cdot 7 \\
(6 \cdot 4,11 \cdot 2) \dagger\end{array}$ & $\begin{array}{c}5 \cdot 8 \\
(4 \cdot 6,7 \cdot 1) \dagger\end{array}$ & $\begin{array}{c}22 \cdot 7 \pm 7 \cdot 4 \\
(4)\end{array}$ & $\begin{array}{c}44 \cdot 6 \pm 12^{*} \\
(5)\end{array}$ & $\begin{array}{c}12 \cdot 6 \pm 4 \\
(3)\end{array}$ \\
\hline 24 & $\longrightarrow$ & - & $\begin{array}{c}16 \cdot 0 \\
(9 \cdot 0,24) \dagger\end{array}$ & $11 \cdot 5 \pm 3 \cdot 8$ & - \\
\hline 25 & - & - & $\begin{array}{c}12 \cdot 0 \\
(1)\end{array}$ & - & - \\
\hline
\end{tabular}

* 2 of these rats had high progesterone levels persisting until the afternoon of Day 23, both died during the night without giving birth.

$\dagger$ Values for the 2 rats in each group that had not given birth by the morning of Day 23.

Indomethacin treatment retarded but did not prevent the decline in plasma progesterone at term. Individual rats varied considerably in their response to indomethacin with regard to plasma progesterone. In some rats $(40 \%)$ plasma progesterone remained elevated $24-48 \mathrm{hr}$ longer than in controls before falling and in $20 \%$ a slow decline was followed by a transient increase on Day 23 . In two animals, plasma progesterone remained high until Days 23 or 24 when the rats died without giving birth, perhaps because luteolysis had been prevented.

Infusions of PGF-2 $\alpha$ on Day 21 were associated with a more rapid decline in plasma progesterone than in saline-infused indomethacin-treated rats, and progesterone concentrations decreased to control levels on Day 22 except in one rat in which progesterone again rose to high levels on Day 22.

Oxytocin infusions had no effect on the decrease in plasma progesterone in indomethacin-treated rats. The onset of spontaneous and oxytocin-induced parturition was always clearly associated with the fall of plasma progesterone to a level below $10 \mathrm{ng} / \mathrm{ml}$ as seen in Table 3 in which the indomethacintreated rats are grouped together according to the course of parturition. 
(a)

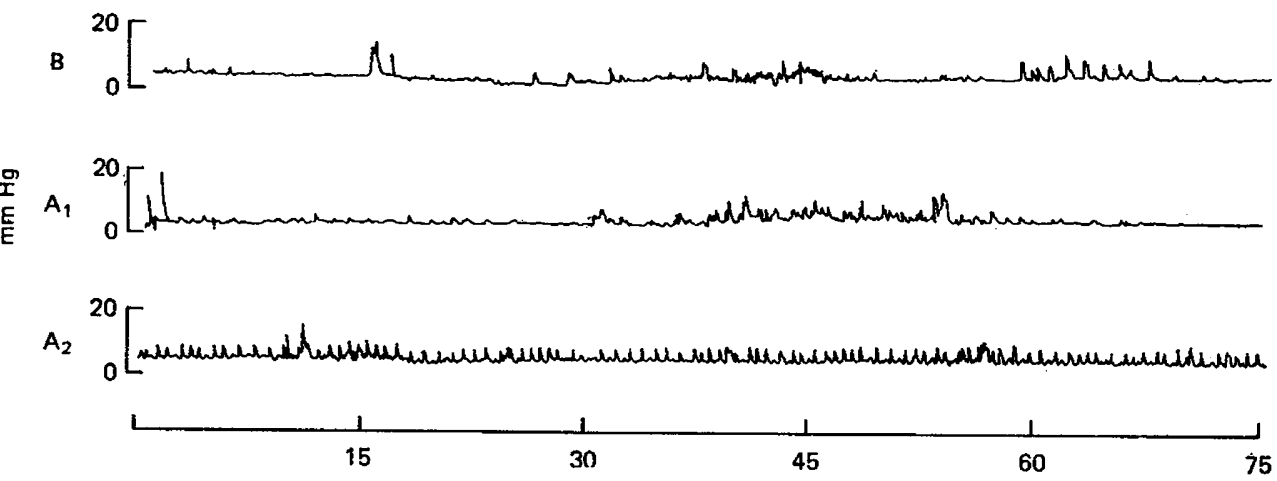

(b).

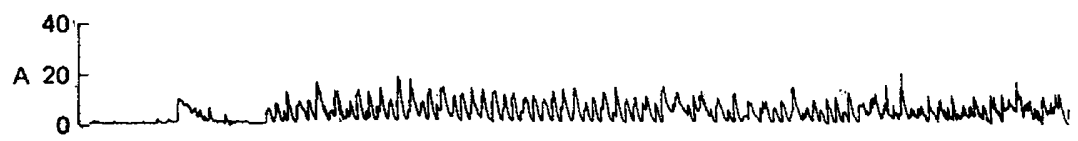

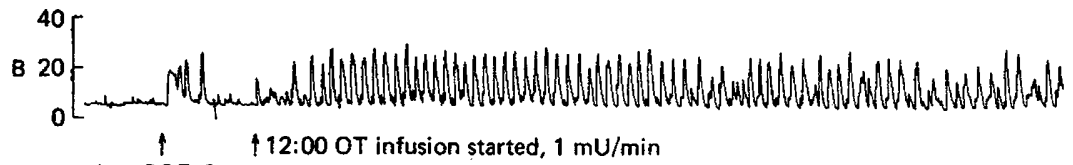

$1 \mu \mathrm{g}$ PGF-2 $\alpha$

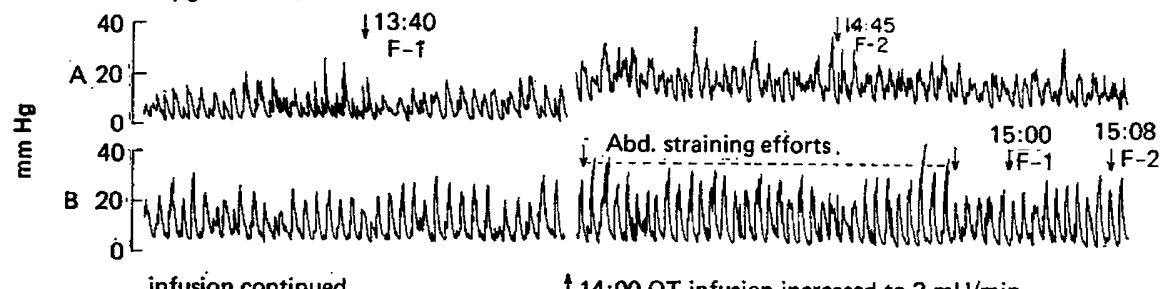

infusion continued $\quad \uparrow 14: 00$ OT infusion increased to $2 \mathrm{mU} / \mathrm{min}$

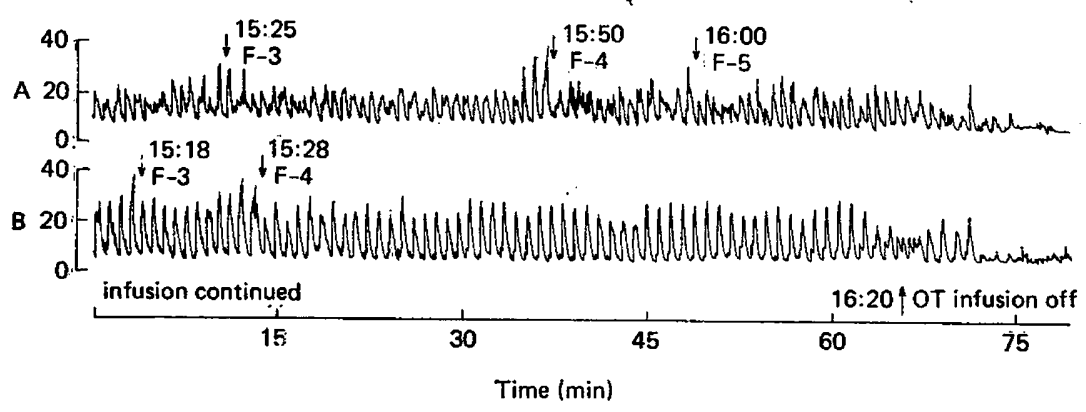

Text-fig. 1. Uterine activity of rats injected with (B) oil or (A) indomethacin. Recordings were made in conscious unrestrained animals by means of an indwelling uterine balloon replacing a fetus in the ovarian end of a uterine horn.

(a) Spontaneous activity on Day 22. The indomethacin treatment was $1 \mathrm{mg} / \mathrm{kg}$ i.m. twice daily $\left(A_{1}\right)$ and 5 $\mathrm{mg} / \mathrm{kg}$ i.m. twice daily $\left(\mathrm{A}_{2}\right)$.

(b) Activity during oxytocin (OT)-induced parturition on Day 22. The times of infusions and expulsion of fetuses $(F)$ are shown. The indomethacin treatment was $1 \mathrm{mg} / \mathrm{kg}$ i.m. twice daily. 
(c)



${ }^{A_{1}}{ }^{40}{ }^{20}[-$

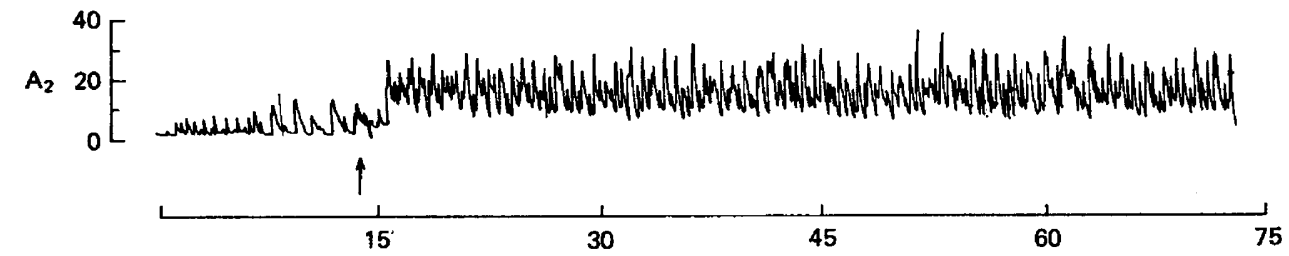

(d)

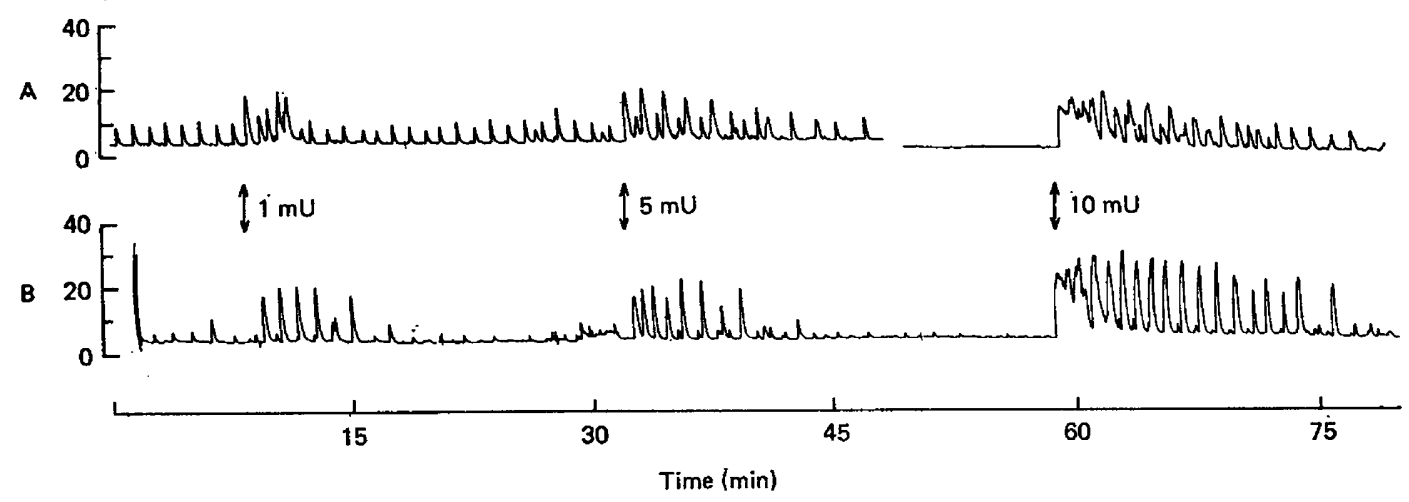

Text-fig. 1 (cont.)

(c) Activity on Day 21 during infusion of $1 \mathrm{mU}$ oxytocin/min (arrow). $\mathrm{A}_{1}, 1 \mathrm{mg}$ indomethacin $/ \mathrm{kg}$ i.m. twice per day; $\mathrm{A}_{2}, 5 \mathrm{mg}$ indomethacin $/ \mathrm{kg}$ i.m. twice per day.

(d) Response to different doses of oxytocin. Indomethacin treatment was $1 \mathrm{mg} / \mathrm{kg}$ i.m. twice a day. 
Table 3. Mean \pm S.E.M. plasma progesterone levels $(\mathrm{ng} / \mathrm{ml})$ in indomethacin-treated rats ( $1 \mathrm{mg} / \mathrm{kg}$ i.m. twice a day) (no. in parenthesis) in relation to the course of parturition

\begin{tabular}{lccccc}
\hline & \multicolumn{5}{c}{ Day of gestation } \\
\cline { 2 - 6 } \multicolumn{1}{c}{ Parturition } & 20 & 21 & 22 & 23 & 24 \\
\hline Normal, at normal time & $73 \pm 7 \cdot 8$ & $56 \pm 9 \cdot 1$ & $12 \pm 2 \cdot 3$ & 9 & - \\
Protracted, delayed in onset & $83 \pm 9 \cdot 2$ & $64 \pm 4.9$ & $41 \pm 8.9$ & $34 \pm 9 \cdot 5$ & $13 \pm 3 \cdot 8$ \\
& $(13)$ & $(13)$ & $(12)$ & $(9)$ & $(5)$ \\
\hline
\end{tabular}

\section{Oestradiol levels}

Oestradiol levels were determined in oil-injected controls (Group 1) and in indomethacin-treated rats given either saline (Group 4) or PGF-2 $\alpha$ on Day 21 (Group 6) (5-8 rats/group). Oestradiol levels varied from 100 to $700 \mathrm{pg} / \mathrm{ml}$ without significant differences between control and indomethacintreated animals, although in rats in which parturition was significantly delayed the plasma oestradiol decreased. The mean plasma oestradiol concentration was $270 \pm 32 \mathrm{pg} / \mathrm{ml}$ on Day 20 in all 3 groups. A moderate increase was observed in control rats in the afternoon of Day 20 which was absent in the indomethacin-treated rats, but due to the large individual variations this difference did not achieve statistical significance. Administration of PGF-2 $\alpha$ on Day 21 to the indomethacin-treated rats had no effect on the plasma oestradiol levels.

\section{Ovarian 20a-hydroxysteroid dehydrogenase activity}

On Day 20 20 $\alpha$-HSD activity was absent from the ovaries of control and indomethacin-treated rats. On Day 22 the ovaries from 6 control rats exhibited strong activity in all corpora lutea (CL) of pregnancy. Of 9 rats treated with $1 \mathrm{mg} / \mathrm{kg}$ indomethacin twice daily, the ovaries of 5 showed no activity, of 2 rats showed weak to moderate activity and of 2 rats showed strong activity, while all CL of rats treated with PGF-2 $\alpha$ on Day 21 had strong $20 \alpha-$ HSD activity on Day 22 . Inhibition of $20 a-H S D$ activity on Day 22 by indomethacin was dose dependent, as seen from the results presented in 'Table 4. This inhibition was only temporary and $20 \alpha-\mathrm{HSD}$ activity appeared on Day 23 or 24.

Table 4. Number of rats with histochemically demonstrable $20 \alpha$ hydroxysteroid dehydrogenase activity in the CL of pregnancy on the morning of Day 22, following treatment with various doses of indomethacin injected i.m. twice a day beginning on Day 20, correlated with mean \pm S.E.M. plasma progesterone levels determined in blood obtained just before removing the ovaries

\begin{tabular}{ccccc}
\hline \multirow{2}{*}{$\begin{array}{c}\text { Indomethacin } \\
(\mathrm{mg} / \mathrm{kg})\end{array}$} & $\begin{array}{c}\text { No. of } \\
\text { rats }\end{array}$ & $\begin{array}{c}\text { Progesterone } \\
(\mathrm{ng} / \mathrm{ml})\end{array}$ & Present & Absent \\
\hline 0 & 6 & $23 \pm 2 \cdot 1$ & 6 & 0 \\
1 & 9 & $35 \pm 2 \cdot 5$ & 4 & 5 \\
1.5 & 7 & $41 \pm 6 \cdot 2$ & 2 & 5 \\
3.0 & 4 & $44 \pm 9 \cdot 6$ & $(1)$ & 3 \\
\hline
\end{tabular}

\section{Discussion}

The results of the present investigation indicate that the interference with the normal course of parturition observed in indomethacin-treated rats is due to a partial inhibition of luteolysis, prolonging the secretion of progesterone which normally has ceased by Day 22 . In no instance was luteal regression completely prevented, but it is possible that the dose of indomethacin was not sufficient. 
A higher dose inhibited the appearance of $20 \alpha-\mathrm{HSD}$ activity in the CL more completely but was too toxic for prolonged use. While this work was in preparation, Strauss, Sokolski, Caploe, Duffy \& Mintz (1975) reported similar findings on the effect of indomethacin on plasma progesterone in parturient rats.

The fact that PGF-2 $\alpha$, given on Day 21, reversed the effects of indomethacin on plasma progesterone levels and on the activation of luteal $20 \alpha-\mathrm{HSD}$, and restored the subsequent course of parturition to normal, strongly suggests that the effects of indomethacin were brought about by inhibition of PG synthetase, although direct proof for this postulate is not provided by these experiments. We have previously shown that the luteolytic effect of PGF- $2 \alpha$ in pregnant rats is always associated with the induction of $20 \alpha-H S D$ activity, and suggested that PGF- $2 \alpha$ lowers plasma progesterone by increasing the ovarian conversion of progesterone to $20 \alpha$-dihydroprogesterone (Fuchs et al., 1974; Fuchs \& Mok, 1974). It is possible, therefore, that the normal activation of luteal 20 $\alpha$-HSD near term is a PG-mediated event, since indomethacin inhibits this activation to some extent.

While indomethacin treatment impeded the process of parturition severely in some rats, others appeared almost unaffected. The reasons for this variability in the response to the drug are not clear without knowledge of the prevailing plasma levels of indomethacin in the experimental animals: the rate of metabolism of the drug may vary from rat to rat; the susceptibility of uterine and ovarian PG synthetases to indomethacin inhibition may also vary from rat to rat, and this can only be resolved by measurement of tissue PG levels.

Contrary to the findings in vitro quoted earlier, indomethacin treatment had no inhibitory effect on spontaneous or oxytocin-induced uterine contractions. The contractility pattern was altered in many instances, but this was due to the elevated plasma progesterone levels. We have shown that in rats uterine contractions are not inhibited by progesterone (Fuchs, 1974, 1975), but the contractions remain local, and the rapid conduction of contraction waves along the uterine horn seen in oestrogendominated animals is absent. This renders the contractions inefficient for propulsion of the uterine contents, and parturition can proceed normally only when well propagated contractions occur (Csapo, 1969; Fuchs \& Poblete, 1970; Fuchs, 1973). The absence of the rise in plasma oestradiol seen in control rats on Day 20 may have contributed to the observed prolongation of parturition in indomethacin-treated rats; but the delay and impairment of parturition by indomethacin can mainly be attributed to its effects on plasma progesterone.

Perinatal and maternal mortality was high. The main maternal side effects were intestinal ulcerations, lowering of haematocrit and some vaginal bleeding. The cause of the perinatal deaths was not immediately apparent. It was often but not always associated with difficult births. However, since the mortality rates were almost normalized by PGF- $2 \alpha$ treatment on Day 21 , it seems likely that neonatal and maternal deaths were attributable to the inhibitory effect of indomethacin on PG synthesis. The fetus is considered to play an active part in triggering the onset of parturition in many species. Although this has not been demonstrated in the rat, it could be argued that the high incidence of fetal death in itself could have caused the delay in the onset of parturition in indomethacin-treated rats. Since most of the fetal loss occurred in the immediate perinatal period, when parturition was already in progress, this seems unlikely. It has been reported that indomethacin administered to the mother can cause closure of the fetal ductus arteriosus (Sharpe, Thalme \& Larsson, 1974) and that PGE-2 and PGF-2 $\alpha$ were able to re-open the closed ductus (Sharpe \& Larsson, 1975). Such a mechanism might explain the perinatal deaths observed in the present study. It has recently been demonstrated that the stillbirth rate was significantly increased among women who used aspirin regularly during pregnancy (Collins \& Turner, 1975b). This raises serious questions about the use of indomethacin and other aspirin-like drugs for treatment of premature labour in women.

Although in rats the main effect of indomethacin appears to be inhibition of luteolysis, this mechanism can hardly be responsible for the prolongation of gestation in primates and it remains to be seen whether uterine contractility, placental hormone production or other factors are influenced by anti-inflammatory drugs in pregnant women.

We gratefully acknowledge the help of Dr E. D. B. Johansson, Uppsala, Sweden, in measuring 
the plasma progesterone and oestradiol levels. This study was supported by a grant from The Population Council to Chulalongkorn University Medical School.

\section{References}

AIKEN, J.W. (1972) Aspirin and indomethacin prolong parturition in rats: evidence that prostaglandins contribute to expulsion of foetus. Nature, Lond. 240, 22-25.

BALOGH, K. (1964) A histochemical method for the demonstration of $20 \alpha$-hydroxysteroid dehydrogenase activity in rat ovaries. $J$. Histochem. Cytochem. 12, 670-673.

Baudouin-Legros, M., Myer, P. \& Worcel, M. (1974) Effects of prostaglandin inhibitors on angiotensin, oxytocin and PGF- $2 \alpha$ contractile effects on the rat uterus during the oestrous cycle. Br.J. Pharmac. 52, 393-399.

Chester, R., Dukes, M., Slater, S.R. \& Walpole, A.L. (1972) Delay of parturition in the rat by antiinflammatory agents which inhibit the biosynthesis of prostaglandins. Nature, Lond. 240, 37-38.

Collins, E. \& Turner, G. (1975a) Maternal effects of regular salicylate ingestion in pregnancy. Lancet $\mathbf{i}$, 335-337.

Collins, E. \& Turner, G. (1975b) Foetal effects of regular salicylate ingestion in pregnancy. Lancet ii, 338-341.

CSAPO, A. (1969) The four direct regulatory factors of myometrial function. In Progesterone: its Regulatory Effect on the Myometrium (Ciba Found. Study Group No. 34), pp. 13-42. Eds G.E.W. Wolstenholme \& J. Knight. Churchill, London.

EdQvist, L.-E. \& Johansson, E.D.B. (1972) Radioimmunoassay of oestrone and oestradiol in human and bovine peripheral plasma. Acta endocr., Copenh. 71, 716-730.

Flower, R.J. (1974) Drugs which inhibit prostaglandin biosynthesis. Pharmac. Rev. 26, 33-64.

Fuchs, A.-R. (1969) Uterine activity in late pregnancy during parturition in the rat. Biol. Reprod. 1, 344-353.

Fuchs, A.-R. (1972) Prostaglandin effects on rat pregnancy. I. Failure of induction of labor. Fert. Steril. 23, 410-416.

Fuchs, A.-R. (1973) Parturition in rabbits and rats. Mem. Soc. Endocr. 20, 163-185.

FucHs, A.-R. (1974) Prostaglandin-induced uterine contractions enhanced by progesterone. Am. J. Obstet. Gynec. 118, 1093-1098.

Fuchs, A.-R. (1975) Regulation of uterine contractility in rabbits and rats. In Physiology and Genetics of Reproduction, pp. 403-422. Eds F. Fuchs and E.M. Coutinho. Plenum, New York.

Fuchs, A.-R. \& Fuchs, F. (1963) Spontaneous motility and oxytocin response of the pregnant and non-pregnant human uterine muscle in vitro. $J$. Obstet. Gynec. Br. Commonw. 70, 658-664.

Fuchs, A.-R. \& MoK, E. (1974) Histochemical study of the effects of prostaglandins $F-2 \alpha$ and $E$ on the corpus luteum of pregnant rats. Biol. Reprod. 10, 24-38.

Fuchs, A.-R. \& Poblete, V.J., JR (1970) Oxytocin and uterine function in pregnant and parturient rats. Biol. Reprod. 2, 387-400.

Fuchs, A.-R., Mok, E. \& Sundaram, K. (1974) Luteolytic effects of prostaglandins in rat pregnancy, and reversal by luteinizing hormone. Acta endocr. Copenh. 76, 583-596.

Fuchs, A.-R., Smitasiri, Y. \& Chantaraksri, U, (1974) Prostaglandin and the onset of parturition in rats. Gynec. Invest. 5, 30 Abstr.

KARIM, S.M.M. (1975) Prostaglandins and Reproduction. University Park Press, Baltimore.

Lewis, R.B. \& SChulmaN, J.D. (1973) Influence of acetylsalicylic acid, an inhibitor of prostaglandin synthesis, on the duration of human gestation and labour. Lancet, ii, 1159-1161.

Novy, M. J., Cook, M.J. \& Manaugh, L. (1974) Indomethacin block of normal onset of parturition in primates. Am.J. Obstet. Gynec. 118, 412-416.

Sharpe, G.L. \& Larsson, K.S. (1975) Studies on the closure of the ductus arteriosus. X. In vivo effect of prostaglandins. Prostaglandins 9, 703-720.

Sharpe, G.L., Thalme, B. \& Larsson, K.S. (1974) Studies on closure of the ductus arteriosus. IX. Ductal closure in utero by a prostaglandin synthetase inhibitor. Prostaglandins 8, 363-368.

Strauss, J.F., Sokolski, J., Caploe, P., Duffy, P. \& MiNTz, G. (1975) On the role of prostaglandin in parturition in the rat. Endocrinology 96, 1040-1043.

ThoRNEYCROFT, I.H. \& STONE, S.C. (1972) Radioimmunoassay of serum progesterone in women receiving oral contraceptive steroids. Contraception 5, 129-146.

VANE, J.R. \& WILLIAMS, K.I. (1973) The contribution of prostaglandin production to contractions of the isolated uterus of the rat. Br.J. Pharm. 48, 629-639.

WiesT, W.G. \& KIDWELl, W.R. (1969) The regulation of progesterone secretion by ovarian dehydrogenases. In The Gonads, pp. 293-325. Ed. K. McKerns. Appleton Century Crofts, New York.

Williams, K.I., Sneddon, J.M. \& Harney, P.J. (1974) Prostaglandin production by the pregnant rat uterus in vitro and its relevance to parturition. Br.J. Pharm. 26, 207-215. 